\title{
A focus on students' use of Twitter - their interactions with each other, content and interface
}

\author{
Sarah Prestridge \\ Griffith University, Australia
}

\begin{abstract}
In their advertising campaigns, universities depict students using computers, laptops, mobile phones, iPads and tablets as learning devices. Regardless of the marketing used, there is value in enlisting the advantages of any medium that can aid deep thinking and increase student engagement. This study offers new knowledge about conceptualising Twitter as a knowledge construction tool leveraged through mobile devices. A qualitative approach was conducted to investigate the learning outcomes of students' use of Twitter when it was implemented as a learning device. The use of Twitter was investigated to provide insight into the ways students and instructors interacted in this environment, how the content was made active and how the functionality of the tool and its conceptualisation impedes and/or supports the learning process. The results indicate that student-initiated interaction supported by instructor use of participatory pedagogies enables substantive dialogue through Twitter and that paraphrasing was the most common way students made learning active.
\end{abstract}

\section{Keywords}

active learning, higher education, social networking tools, Twitter

\section{Tweeting and learning}

\section{An introduction to Twitter}

Twitter is part of the social networking phenomenon of Web 2.0 technologies. Such social networking tools are described by Boyd and Ellison (2007) as pervasive in daily life. Twitter can be thought of as the Short Message Service (SMS) of the Internet as it allows its users to send and read text-based messages of up to 140 characters. Twitter users post messages, 'tweets', read by users who follow that person or use the same Twitter hashtag (Anderson, 2011). A tweet can include text and links to photos or videos and can also be 'retweeted' for further distribution among followers. In an educational context, tweets can be constructed to express an idea, paraphrase or critique a concept, provide a level of discourse in a virtual space that supports dialogue occurring face to face (Sweeney, 2012). The Twitter stream can also provide a record of the event (lecture, presentation, meeting) from the perspective of the participants. Twitter is a 
tool that is considered popular with today's students (Taylor and Keeters, 2010) who use technologies as part of their seamless social interactions.

Online education requires students to engage in self-regulated learning, which is a more difficult learning process (Oliver, 2001). It has been plagued by issues of students feeling isolated and a lack of engagement between students and with the instructor, all of which can lead to disengagement and higher drop-out rates (Veletsianos and Navarrete, 2012). Herrington et al. (2005) identify that online courses have a product orientation for information delivery and they call for a move to more innovative, authentic pedagogies refocusing on course delivery for learning outcomes.

The rise of social networking sites (SNSs) with their disposition for a sharing and knowledgeproducing exchange logically suggests a merger with education to improve teaching and learning outcomes. However, one of the first moves to online learning in higher education has been to employ a learning management system (LMS). LMSs like the Blackboard ${ }^{\odot}$ platforms direct students to engage in ways that are different to SNSs. LMSs serve as management systems that support administrative concerns and use communication management tools more frequently than interactive tools (Dalsgaard, 2006). LMSs also engender teacher-centred pedagogies for distributing course content. This has impact on how content and student interaction occurs. In an LMS, the instructor provides the content, which is central to activity, whereas in an SNS the content is generated by the user and interaction is the central activity (Mott, 2010).

Engagement between student and the content is also different. For example, an instructor in an LMS may pose a question in an online discussion board with each student posting a response, replicating traditional question-and-answer mode. In contrast, discussion in an SNS is selfdirected or student centred (Brady et al., 2010). Veletsianos et al. (2013) suggest that an SNS fosters the use of participatory pedagogies and is able to support interactive discussions. Interaction and content are more free-flowing and therefore are more difficult to control. Marwick and Boyd (2010) found that tensions arise when SNSs have been used in higher education as personal and professional boundaries for instructors collapse as sites are not conducive to teacher-centred pedagogies.

Developing a sense of community is critically important to student engagement in any online learning environment - LMS or SNS - especially if students do not meet face to face. The tools used in an SNS facilitate the sharing of information. This plus personal profiling and a student's sense of social presence are key factors that promote a community of practice (Cobb, 2009; DeSchryver et al., 2009). LMSs have been described as tools that fail to provide users with the social presence necessary for more robust and valuable networking experiences that are essential for learning (Minocha, 2009; Veletsianos and Kimmons, 2013). Therefore, social presence and its critical relationship to building a community of practice indicate the potential of SNSs in education.

The employment of social networking tools in higher education has been viewed as one way to address these problems with the tools potential to enable a sense of presence, build community and support student participation in interactive discussions through participatory practices. Learning in this way has its foundations in social constructivist theories (Smith and Ragan 2005). This literature reveals a pedagogical shift towards a constructivist paradigm, of enabling critique, collaboration and co-construction of knowledge where the learners engage in 'knowledge construction, not reproduction; conversation, not reception; articulation, not repetition; collaboration, not competition; reflection, not prescription' (Jonassen et al., 2003: 15). There is also a significant emphasis on enabling conversation to support social negotiation and collaboration in learning (Jonassen, 1999) where the teacher takes on the role of guide or knowledgeable mentor. From a sociological perspective, Beer and Burrows (2007) acknowledge SNSs as reworking hierarchies, changing social divisions, creating possibilities and 
opportunities, informing us and reconfiguring our relations with objects, spaces and each other. Brown and Alder (2008) suggest that learning with Web 2.0 tools is so different that it should be called 'Learning 2.0' (p. 30) to emphasise a new learner-centric paradigm that facilitates innovative explorations, experimentations and purposeful tinkering, which often forms the basis of a situated understanding emerging from action, not passivity.

\section{Twitter in higher education}

The use of Twitter in higher education is in its infancy (Betrus, 2012). Reuben (2008) suggests that there is great potential in education for the use of social networking tools such as Facebook and YouTube; however, higher education has not yet found the right niche for Twitter. In the domain of health and medicine, Fox and Varadarajan (2011) incorporated Twitter as a way to encourage interaction between students themselves, with the academic teaching staff and with the content of the course. A Twitter activity was implemented whereby students were required to post a minimum amount of tweets per class for a percentage of their grade. If the minimum number of tweets were executed, the student received the full mark. Results indicated that increased interaction occurred between course participants in that students voiced their opinions and shared ideas. Interestingly, this research was quantitative by design as results were based on the number of tweets and number of positive and negative feedback comments. The contents of the tweets were not analysed for the meaningfulness of the interaction they provided. Use of Twitter as part of assessment in a course was also reported by Turcsányi-Szabo (2012). In a teacher pre-service education course focused on understanding how to use technologies in the classroom, Turcsányi-Szabo (2012) reported the use of Twitter as an important part of students building a personal learning network. Students were required to tweet their 'Aha' (p. 123) experiences as they developed assessment items throughout the course.

Other studies have investigated live tweeting during lectures and tutorials (Croxall, 2010; Parry, 2008). As found by these researchers and by Fox and Varadarajan (2011), Twittering during course instruction is perceived by students as a distraction to listening and taking notes. However, Croxall (2010) and Parry (2008) both describe the development of greater social interaction and the notion of course community arising from their anecdotal use of Twitter in their lectures.

Reid (2011) investigated the opportunities that social networking environments like Twitter and Facebook offer in regard to social, emotional and academic development. She conceptualises these online environments as 'safe spaces' as power relationships are altered, informal speak can be used and ideas are unrestricted. Her results indicate that Facebook can provide opportunities for academic networking to aid the process of learning in course work.

With regard to student-learning outcomes, researchers have also examined Twitter as a tool to support informal learning beyond the classroom (Ebner et al., 2010; Kassens-Noor, 2012). In her approach, Kassens-Noor (2012) designed assessment whereby students communicated through Twitter and tweeted specific tasks daily over a period of time as a collaborative approach to learning course content. Results indicated that Twitter facilitated sharing of ideas beyond the classroom walls but limited reflective thinking. Tweeting, described by Ebner et al. (2010) as micro-blogging, was investigated for its ability to support informal learning, defined as the process that students engage in any given course. Twitter was found to have great potential for informal learning based on the evidence of high level of 'small talk' between students, as Ebner et al. (2010) state that 'informal learning will only occur if there is an opportunity to talk with each other without any constraints' and that 'the opportunity to be a part of someone else's process by reading, commenting, discussing or simply enhancing it' indicates engagement in the learning process (p. 99). 
The literature reviewed here has identified issues, challenges and potentials for the use of Twitter in tertiary courses. All researchers and academics who have trialled the use of Twitter in their course work have done so to support the needs, interests and learning styles of our current student cohorts. The affordances for use of Twitter identify its orientation for participatory pedagogies, the development of social presence and a community of practice, a learning orientation in terms of its process rather than its product, with knowledge construction generated through user engagement in free-flowing discourse. Research is limited by quantitative evidence of engagement focused on the number of tweets. A more robust examination could be derived from qualitative research that investigates how students are engaging, how they generate knowledge, the ebb and flow of discourse, the types of interaction that occur between student/s and lecturer, to better understanding the potential, impact and approach to learning that this tool can offer. There is still much that we do not yet know about the precise nature of these tweets. For example, it is common for the lecturer/instructor to stimulate tweets by tweeting a question to the student body based on what was covered in the lecture. Is it normal for students to answer these stimulus questions? Another common practice for a lecturer is to leave some or all student questions unanswered in order to see if other students respond, but there is a lack of data in the literature that tells us whether or not this 'works' or what response, if any, there is from other students. The idea that students self-generate knowledge changes the role of the lecturer and the pedagogical approach, and raises issues with regard to content delivery and assessment. Also of interest is how Twitter is used in a course, either as a pedagogical tool or an assessment tool. In the research presented here, the more common approach is to use Twitter as a requirement of assessment. There is a lack of research on how students use Twitter as a tool to learning without assessable requirements.

There is also a lack of examination in the literature that identifies the conceptualisation that students have of Twitter as a tool for their learning in higher education. Research has focused on exploring active learning and informal learning but it does not qualify activity. Two questions are raised from this issue. First, is Twitter a tool where students can learn in active ways and specifically how do students make course content active using Twitter? Being an active learner means that students do something with the content. What is lacking in the literature is exactly what students do with course content using Twitter. This can aid our understanding of informal learning and how it can contribute to student knowledge construction as well as how it can inform course content implementation. Second, how do students conceptualise Twitter and what impact does this have on its use in course work; that is, can they see it as a tool to help them learn academically? Twitter as a social networking tool is more commonly used to keep up to date with small quantities of information, as presented in the literature reviewed. How students use Twitter, its functionality and how they conceptualise it in an academic realm will affect how it is used. This ultimately can enhance or impede its use within course work.

In response to this literature review, this study will investigate three areas: first, an examination of the types of interactions between students and lecturer; second, an in-depth examination of how students action course content in what could be defined as active learning using Twitter; and third, how students conceptualise Twitter as a tool for learning and what impact this has for its educational potential.

\section{Methodology}

This study provides a qualitative enquiry into the use of Twitter. A qualitative approach provides a paradigm that enables the researcher to gain deeper insights into the types of interactions students engage in when using Twitter, rather than the number of tweets or student feedback on an experience that would be gained though quantitative methods. Rather, this research looks at 
the tweets as data, the interchange of tweets, the content of the tweets to seek answers to the following questions:

1. What types of interaction occur between lecturer and student using Twitter during a course?

2. How do students interact with content and generate knowledge using Twitter?

3. How do students conceptualise Twitter with regard to it being a learning tool?

Qualitative enquiry is dependent upon context. Context is viewed as a 'complex web of unique interrelationships' (Erlandson et al., 1993: 16) within which the researcher is a participant, mutually shaping constructed reality. What is considered real is a construction in the minds of individuals (Lincoln and Guba, 1985). Constructions are not seen in terms of truth in the absolute sense but in terms of 'the best informed and most sophisticated construction on which there is a consensus at a given time' (Schwandt, 1994: 128). The personal nature of these social constructions suggests that individual construction can be elicited and refined only through 'interaction between investigator and respondent' (Guba and Lincoln, 1994: 111). The task of the researcher is to make known the multiple, often conflicting social constructions of meaning and knowledge. The researcher is considered a research instrument through which data are understood. In this research, the lecturer was the researcher, the first-year pre-service students were the respondents and the tweets constructed through Twittering provided the rich data.

\section{Participants}

The Pre-service Teacher Education Studies course in which Twitter was trialled was implemented as part of the roll-out of a new Bachelor of Education programme. The course was implemented for the first time in the second semester of 2012. As there was no precedence for implementation, it was considered an opportunity to trial new approaches to learning. The course is considered fundamental to the programme as it involves the students in their first practical experience as pre-service teachers in classroom. The course involves the students in 13 weeks of lectures and tutorials plus 10 days classroom practical experience. The course was implemented over two campuses. All 180 students enrolled in the course were invited to participate.

\section{Design and procedure}

A hashtag with the course code was set up by the lecturer and introduced in the first lecture. All participants were invited to tweet throughout the lecture and at any point in time over the duration of the 13-week course, including all lectures, tutorials, when reading course materials or completing activities outside of contact time. The lecturer did not provide any technical training as this was considered assumed knowledge and if technical support was required, students were encouraged to help each other, which is in keeping with the development of a learning community. The lecturer asked students to tweet about content during lectures and tutorials with both verbal and visual reminders. The lecturer also posted stimulus questions outside of lecture times and reviewed tweets that had been posted during the subsequent lectures to raise issues and questions and to draw attention to student understanding.

Unlike Fox and Varadarajan (2011), Kassens-Noor (2012) and Turcsányi-Szabo's (2012) use of Twitter as part of an assessable item in their courses, this course did not mandate the use of Twitter. Rather the rationale for use of Twitter in the course was grounded in a constructivist paradigm through the use of participatory pedagogies (Veletsianos et al., 2013), whereby the 
Table 1. Types of interactions and guiding questions.

\begin{tabular}{ll}
\hline Type of interaction & Guiding questions for research \\
Learner-learner-instructor & $\begin{array}{l}\text { What types of interactions occur between the student(s) and the } \\
\text { lecturer? }\end{array}$ \\
Learner-content & How do students interact with content and generate knowledge? \\
Learner-interface & $\begin{array}{l}\text { How do students conceptualise Twitter as a tool for learning, and how } \\
\text { does this impact its educational potential? }\end{array}$ \\
\hline
\end{tabular}

lecturer encouraged and stimulated tweets between and among the student body, adopting a learner-centred approach rather than a teacher-directed approach. Participatory pedagogies are described by Askins (2008) as teaching that recognises and foregrounds students as knowledgeable agents, where the instructor avoids projecting his or her position or opinion on a topic and empowers the student to 'speak' without necessarily using their voices, such as in tweeting. Additionally, in this course Twitter was implemented to support the development of a learning community, often referred to as a Community of Practice (Wenger 1998) within an SNS, discussed in the literature section as beneficial to enabling greater interaction of the student. Also as this research is grounded in an interpretivist paradigm, all participant students' and lecturers' tweets were considered data derived from what Sharpe (2006) describes as at a 'more appropriate moment to an individual' (p. 16), that is, when the participant (student or instructor) chose to tweet. All tweets were collected by the researcher through a systematic copying and pasting process.

\section{Data analysis}

Based on the findings in the literature review for more in-depth understanding of how students interact when using Twitter, a framework was drawn together based on research into types of interaction in the context of distance education. Research provided by Moore (1989) proposes three types of interaction in distance education, these being, learner-content, learner-instructor and learner-learner. Furthermore, research provided by Hillman et al. (1994) identifies the need for an examination of learner-interface interaction. Guided by the three research questions, a combination of these types of interaction provided a framework for examining the tweets in this research context (see Table 1).

Learner-learner-instructor interactions are interactions that occur between the students, alone or in a group and/or with the instructor. Learner-content interaction occurs when the student intellectually engages with content resulting in changes in understanding. Learner-interface interaction occurs with a focus on the technology as an intermediary between the student and the content. Tweets were analysed for the type of interaction displayed. Tweets were copied in full and within a trail of discourse to ensure context and validity.

\section{Results}

\section{Learner-learner-instructor interaction}

Tweets that fall into this type of interaction include students' individual tweets, retweets, students' tweets to student followers and students' tweets to the lecturer, as well as the lecturers' tweets to individuals and the student group. At the onset of the course, the lecturer was the main instigator of the tweets, which were focused on instructions and encouragement, such as 'during 
\#1701EDN Do you think that improving quality of kindy programs will help children in the long run?

Expand

Figure 1. Lecturer question.

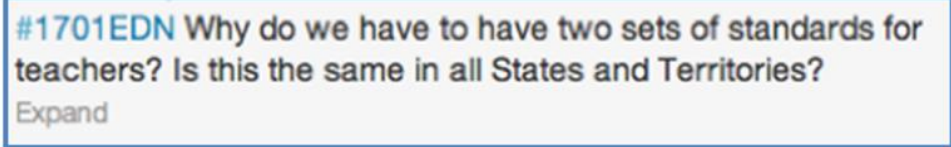

Figure 2. Student-initiated questions.

the lecture tweet about anything interesting'. These types of administrative interactions are requirements at points in time in support of the development of a learning community (Nickerson and Sowder, 2002). To build student engagement, the lecturer tweeted questions that were based on content covered in the lecture (see Figure 1).

This strategy for teacher-led discussion is in keeping with Manning and Payne's (1993) suggestion that the mechanics for growth in the zone (Vygotsky's concept of zone of proximal development) is the actual verbal interaction with a more experienced member of society. In this context, however, students rarely answered these stimulus questions, which is in opposition to Moore's (1989) identification of learner-instructor interaction as being highly desirable by the learner, but it is in keeping with Brady et al.'s (2010) finding that SNSs support greater student self-directed discussion. In this context, questions constructed by the students were more common. Students tweeted questions they had about the course content (see Figure 2). Initially, the lecturer answered these, which would be considered the typical student-teacher dialogue. However, to support student-centred interaction, whereby students responded to each other, the lecturer left student questions unanswered. At no time during the 13-week course did a student answer a question tweeted by another student, even as the course progressed. There was also a lack of retweeting, where a student could have retweeted a fellow student's tweet to emphasise a good point. This indicated a lack of learner-learner interaction in this context.

The major type of interaction between participants in this context was found to be learnerinstructor interaction, whereby a student would initiate dialogue by tweeting a question and the lecturer would respond. The lecturer employed participatory pedagogies to facilitate discussion. This included the use of questioning to extend students' thinking. Substantive interaction between the student and lecturer occurred, evidenced in a 12-tweet conversation over 5 days (see Figure 3). The topic was initially covered in the lecture. The student was stimulated by further reading and began to tweet about her understanding of the concept outside of contact time. The lecturer, through a series of questions, enabled the student to explore the concept in relation to other course content. The learner-instructor dyad is evident here. These findings support Veletsianos et al.'s (2013) findings that the use of SNS fosters the use of participatory pedagogies and are able to support ongoing discussions.

However, in this context learner-instructor interaction was unable to support dialogue if confusion occurred with content. When a student posted a tweet that demonstrated some confusion with the course content and the lecturer responded in a manner to extend thinking, a challenge rather than a direct answer, disengagement occurred. This has been found to be 


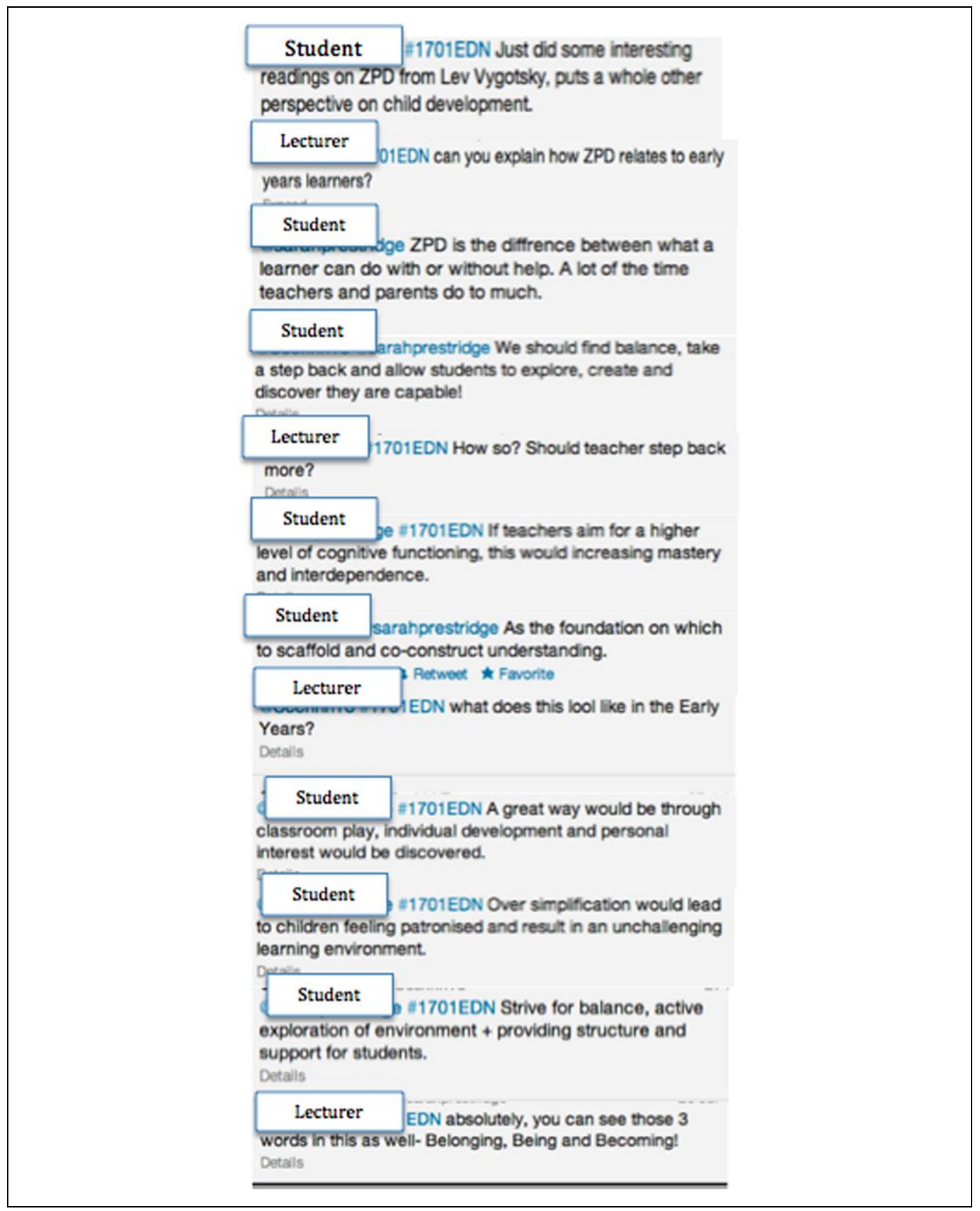

Figure 3.12 tweet learner-instructor interaction.

symptomatic of what Fletcher and Hill (2004) describe as 'collisions' as part of group participation in learning communities. Prestridge (2009) found that such collisions require a strong sense of collegiality within an online community to enable participants to evaluate and work through confusion to remain engaged. 
Figure 4. Paraphrasing.

In summary, learner-instructor interaction was the most evident form of interaction. The interaction was student initiated with support and direction provided by the lecturer through participatory pedagogies. There was evidence of substantial dialogue and engagement between the participants but this was limited to one-on-one interaction rather than among multiple students. Twitter did not support learner-learner interaction other than student tweets to the student body or what is considered in SNSs by Brandtzaeg and Heim (2011) as lurkers who view tweets but do not actively participate. Instructor-learner interactions whereby a stimulus question created impetus for continued dialogue was not evident.

\section{Learner-content interaction}

Enabling students to be active learners, to interact with course content and to support their sense of academic culture is a defining characteristic of education (Moore, 2009). Paraphrasing was a common way students tweeted course content. This has been described by Holmberg (1986) as the internal didactic conversation where students talk to themselves about the information they encounter. This process supports the learner in changing information into knowledge. It also makes thinking conscious and builds students' metacognitive skills. Figure 4 shows an example tweet where the student is building knowledge and understanding of the course content by paraphrasing key points during a lecture. This commonly occurred throughout the lecture series.

It was suggested in a lecture that one way to explore the meaning of a set of teacher standards was to create a Wordle and identify the key words in the resultant image. During the lecture students actioned this idea and posted it on Twitter straight away. This image-tweet was retweeted by other students indicating its value. Other ways that the students interacted with content moved from paraphrasing what was said by the lecturer, to applying the content (see Figure 5). In their tweets, the students' state the key points and demonstrate analysis and application of the content. Learning processes such as analysis and application of content represent higher levels of learning cognition (Jonassen et al., 2003).

Learner-content interaction was evidenced by students paraphrasing, representing and applying the content to their own understandings. Paraphrasing lecture content was common, whereas the application of content through examples provided by students began to emerge as the course progressed. The movement from paraphrasing to applying content indicates active learning processes.

\section{Learner-interface interaction}

This type of interaction focuses on the technology as the student must have the ability to mediate the technology to engage with course content and other participants (Hillman et al., 1994). The student must also understand specific communication protocols to be an active participant and must not disengage, be fearful and or be persistent enough not to give up. These fundamental technological skills are required of the pre-service teacher both academically and professionally. Mishra and Koehler (2006) articulate the pedagogy that is required of teachers to integrate technology, effectively emphasising that teachers need technological knowledge, knowledge of 


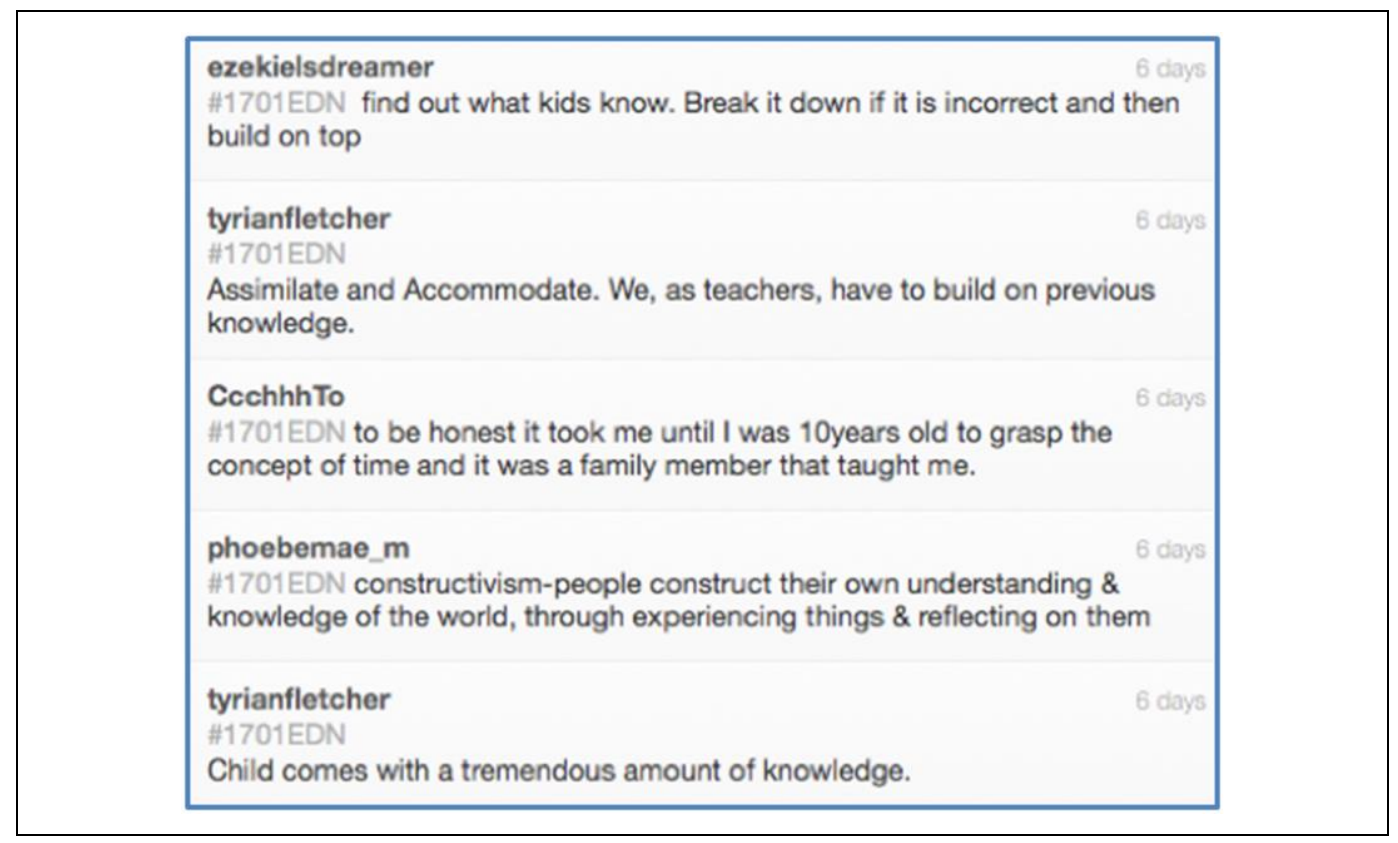

Figure 5. Redesigning the content.

the ways content is changed by the technology and knowledge of the teaching and learning capabilities of various technologies. Using Twitter as a personal learning tool supports development in these areas. Also explored in the literature is the pervasiveness and popularity of SNSs and Twitter (Boyd and Ellison, 2007; Taylor and Keeters, 2010). These understandings signify the importance and familiarity students have for tools such as Twitter; however, the findings of this study on student technological skills and disposition for use are contradictory.

For example, students expressed that they were having trouble getting on to Twitter, and that they became frustrated and missed important content given in the lecture. This is evidenced in tweets such as 'Struggling to take notes and tweet at the same time'. This indicates that students did not see tweets as a form of lecture notes. Students did not recognise that the tweets during the lectures provided an account of the main ideas plus a discourse about the content. This represents an emergent phase of understanding of the functionality of Twitter and a lack of understanding of Twitter as a learning tool.

Further frustrations were evident in student tweets when dialogue was misinterpreted (see Figure 6). Ebonie Jane became 'lost' in the dialogue when a question was posted by the lecturer to extend her thinking. There is evidence here of a frustrated response to learner-interface interaction which could be based on the restrictions imposed by tweets -140 character limit and by the lack of other sensory input that restricts the flow of conversation through digital communication tools. It could also indicate that participatory pedagogies require reaffirming responses rather than challenging responses in this medium.

Learner-interface interaction is important to both conceptualise the type of discourse supported by the technology and the quality of the discourse. As evidenced here, students did not conceptualise tweets as valuable lecture notes, they became frustrated with the interface and at times the discourse was misinterpreted. These findings could be considered symptomatic of the functionality of Twitter; however, these could be overcome with pedagogies that respond to these issues such as reaffirming responses and discussion around the application of Twitter as a learning tool. 
Ebonie Jane Geboniejane

Graangili my top is the same thing but for school age care.. School age care we always under the childcare umbrella but no more... \#1701EDN

Expand

\section{Lecturer}

Geboniejane Graangiii R we always thought of a childcare workers? will the current movement in QLD reinforce that?

- Hideconversation \& Reply - Delete $\star$ Favorite

Ebonie Jane Ceboniejane

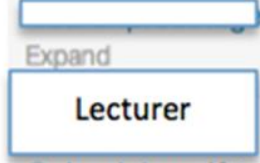

Graangiii I'm lost ?? What's getting reinforced ???

Lecturer

Geboniejane If teachers teach in kindy will this reinforce the idea that we are focused on care not education in the formal sense? Expand

Ebonie Jane Ceboniejane 22 Jul

it's very much play based and generally extends from the child's interests therefore caring for the child's prior knowledge

Figure 6. Display of student misinterpretation.

\section{Conclusion}

Twitter, like any technological tool, can be adapted to the educational context. In reality, Twitter is a social networking tool with functional and conceptual limitations that need to be overcome through pedagogical approaches if it is going to be used effectively as a learning tool. This qualitative study has provided a lens to look deeply into the ways in which students use, conceptualise and interact with Twitter to better understand its adaption to academic engagement. The use of Twitter was investigated in the ways students and lecturer interacted in this environment, the way course content was made active and how the functionality of the tool and its conceptualisation impedes or supports the learning process. The results provide insights into these areas to inform better utilisation of the tool.

Interaction of students through Twitter was illustrated predominately through learnerinstructor interaction where the student posted a tweet about something of interest and the lecturer responded in a manner that supported the flow-on of discourse, discussed here as participatory pedagogies. In this way, the learner chose the concept to discuss and the instructor was responding to their needs. It was evident that interaction did not occur when a question was tweeted by the lecturer, and little student-student interaction occurred. Making content active was exhibited by students in tweets through paraphrasing of lecture content. Paraphrasing was identified as the beginning phase of knowledge development and was considered a vital opportunity to support this process. As the course progressed, students demonstrated active 
learning processes by tweeting images, links, retweeting and eventually applying knowledge to their own contexts. Students struggled both with the functionality of Twitter and the conceptualisation of Twitter as a learning tool as students did not conceptualise tweets as lecture notes.

This study makes four important contributions to our knowledge of the use of Twitter to support deeper engagement in learning. First, Twitter as a communication device should support interaction between the participants in a course. As found throughout the literature, students have been able to share ideas and opinions, build a sense of community, reflect and speak informally (Croxall, 2010, Fox and Varadarajan, 2011, Parry, 2008, Reid, 2011). These types of practices indicate social, emotional and academic engagements. What is missing from the literature was an understanding of what kinds of interaction are more productive to best enable these practices. This study found that student-initiated interaction, through a question or idea tweeted and responded to by the lecturer who then supported and extended the student's thinking, was most supportive of the learning process. This mirrors the traditional pedagogical didactic where a student asks a question/idea and the teacher develops this further, working in a one-to-one relationship. However, what is missing here is the social networking capability of this tool.

This leads to the second contribution of the study - that is, different types of interaction with participants and content are derived from the purpose for the use of Twitter. In this research, Twitter was used as a pedagogical tool not an assessment tool. In this study, there was little student sharing, collaborating or co-constructing that was evident in other studies (Ebner et al., 2010; Kassens-Noor, 2012). This may be due to the fact that no task was set as part of student engagement with the tool. To ensure greater social networking, assessment may need to be associated with its use. Requiring students to do something within course assessment will make them engage differently with the tool.

Third, how students activate content has not been clearly defined in the literature. In this study, Twitter was found to have advantages and limitations when supporting students' interaction with course content. Students were found in this study to paraphrase content, which simply is a way to restate content. This is the fundamental stage for learning, as it makes students act on content. There was movement to applying content but this was towards the end of the course, which is representative of the development of content knowledge over course life. What is interesting is that this environment does not enable the channels for deep thinking, rather that content complexities may be better dealt with in a face-to-face setting, as evident in other online communication tools (Prestridge, 2010). However, thinking about this in a different way, Twitter illuminated what content students were having trouble with, which could then inform future teaching practices.

Finally, in the literature studies have found that Twitter functionality such as 140 characters can limit engagement; however, in this study, the way students conceptualised Twitter was found to significantly impact their engagement with the tool. In this instance, students did not recognise that tweets during the lectures provided an account of the main ideas plus a discourse about the content. They became frustrated with trying to take notes as they were tweeting. This indicates that they did not view the backchannel as a source of rich discourse that activated the lecture content.

This study has several limitations. This study was designed on a qualitative paradigm and method. Unlike most research into Twitter that has quantitative elements, this study sought to investigate the meaningfulness of the interaction in the tweets. It examined interactions between participants, interaction with content and interaction with Twitter itself. All analysis contained bias as interpretations were made through the researcher as a participant in the study. No quantitative analysis was involved. This limited the study in two ways. First, as the number of Tweets was not quantified, patterns of engagement over the given period could not be examined. 
This leads to another limitation, in that types of tweets could not be aligned to those students who were high engagers or low engagers and/or lurkers. Further research could combine both methodologies to investigate why and how students are Twittering more or less and the types and meanings of tweets they post. Of major importance identified here was the lack of use of social networking. A key direction for further study and use of Twitter is to enable the potential of social discourse through pedagogical applications without the assessment requirements.

The findings of this research have implications for the use of Twitter. As Kassens-Noor (2012) suggests in an outcome of her research, 'different approaches to teaching and learning' (p. 19) with Twitter need to be examined. This study implemented a pedagogical approach that focused on enabling students to action their learning with Twitter. In this case, greatest interaction occurred when the instructor supported discourse generated by the student while its use was not associated with assessment. Additionally, realisations that emerged from the use of Twitter include an understanding that complex concepts presented in lectures can be simplistically dealt with in tweets in encouraging ways as part of the learning process but complexities need face-to-face exploration before they can be critiqued in this environment. This illustrates the development of understanding and knowledge construction that occurs through the life of a course and can be supported in students' tweets moving from paraphrasing to applying content. Also underlying the use of Twitter is the clear conceptualisation that tweets can be considered rich discourse around course content, such as lecture notes and that they action information into knowledge and therefore have a clear role to play in learning.

\section{Funding}

This research received no specific grant from any funding agency in the public, commercial or not-for-profit sectors.

\section{References}

Anderson S (2011) The Twitter toolbox for educators. Teacher Librarian 39(1): 27-30.

Askins K (2008) In and beyond the classroom: Research ethics and participatory pedagogies. Area 40(4): $500-9$.

Beer D and Burrows R (2007) Sociology and, of and in Web 2.0: Some initial considerations. Sociological Research Online 12(5): Article 17.

Betrus A (2012) Historical evolution of instructional technology in teacher education programs: A ten-year update. TechTrends 56(5): 42-5.

Boyd D and Ellison N (2007) Social network sites: Definition, history, and scholarship. Journal of Computer: Mediated Communication 13(1): 210-30

Brady K, Holcomb L and Smith B (2010) The use of alternative social networking sites in higher educational settings: A case study of the e-learning benefits of Ning in education. Journal of Interactive Online Learning 9(2): 151-70.

Brandtzaeg P and Heim J (2011) Typology of social networking sites users. International Journal of Web Based Communities 7(1): 28-51.

Brown J and Adler R (2008) Minds on fire: Open education, the long tail, and learning 2.0. Educause Review 43(1): 16-32.

Cobb SC (2009) Social presence and online learning: A current view from a research perspective. Journal of Interactive Online Learning 8(3): 241-54.

Croxall B (2010) Reflections on teaching with social media. Chronicle of Higher Education, 7 June, 2010. Available at: http://chronicle.com/blogs/profhacker/reflections-on-teaching-with-social-media/24556 (accessed 17 December 2012).

Dalsgaard C (2006) Social software: E-learning beyond learning management systems. European Journal of Open, Distance and E-Learning EURODL 9(2). Available at: http://www.eurodl. org/materials/contrib/ 2006/Christian_Dalsgaard.htm (accessed 15 July 2012). 
DeSchryver M, Mishra P, Koehler M, Francis, A (2009) Moodle vs. Facebook: Does using Facebook for discussions in an online course enhance perceived social presence and student interaction? In: Proceedings from the society for information technology and teacher education international conference 2009 (ed. C Crawford, DA Willis, R Carlsen, et al.), Charleston, SC, 2 March 2009, pp. 329-336. Chesapeake, VA: AACE.

Ebner M, Lienhardt C, Rohs M, et al. (2010) Microblogs in higher education - A chance to facilitate informal and process-oriented learning. Computers \& Education 55(1): 92-100.

Erlandson D, Harris E, Skipper B, et al. (1993) Doing Naturalistic Inquiry. A Guide to Methods. Newbury Park, CA: SAGE.

Fletcher M and Hill V (2004) Partnerships in action: Self-directed community learning. In Bartlett, B, Bryer, F, Dick, R (Editors). Educating: Weaving Research into Practice: Volume 2. Nathan QLD: Griffith University, School of Cognition, Languag and Special Education, 2004: 57-68.

Fox B and Varadarajan R (2011) Use of Twitter to encourage interaction in a multi-campus pharmacy management course. American Journal of Pharmaceutical Education 75(5): 1-8 (Article 88).

Guba E and Lincoln Y (1994) Competing paradigms in qualitative research. In: Denzin N and Lincoln Y (eds) Handbook of Qualitative Research. Thousand Oaks, CA: SAGE, pp. 105-17.

Herrington J, Reeves T and Oliver R (2005) Online learning as information delivery: Digital myopia. Journal of Interactive Learning Research 16(4): 353-67.

Hillman D, Willis D and Gunawardena C (1994) Learner-interface interaction in distance education: An extension of contemporary models and strategies for practitioners. American Journal of Distance Education 8(2): 30-42.

Holmberg B (1986) Growth and Structure of Distance Education. London: Croom Helm.

Jonassen D (1999) Designing constructivist learning environments. In: Reigeluth CM (ed.) Instructional Theories and Models, 2nd edn. Mahwah, NJ: Lawrence Erlbaum Associates, pp. 215-39.

Jonassen D, Howland J, Moore J, et al. (2003) Learning to Solve Problems with Technology: A Constructivist Perspective. Upper Saddle River, NJ: Pearson Education Inc.

Kassens-Noor E (2012) Twitter as a teaching practice to enhance active and informal learning in higher education: The case of sustainable tweets. Active Learning in Higher Education. 13(1): 9-21.

Lincoln Y and Guba E (1985) Naturalistic Inquiry. Newbury Park, CA: SAGE.

Manning B and Payne B (1993) A Vygotskian-based theory of teacher cognition: Towards the acquisition of mental reflection and self-regulation. Teaching and Teacher Education 9(4): 361-71.

Marwick A and Boyd D (2010) I tweet honestly, I tweet passionately: Twitter users, context collapse, and the imagined audience. New Media \& Society 13: 114-33.

Minocha S (2009) Role of social software tools in education: A literature review. Education and Training 51(5/6): 353-69.

Mishra P and Koehler M (2006) Technological pedagogical content knowledge: A new framework for teacher knowledge. Teachers College Record 108(6): 1017-54.

Moore M (1989) Editorial: Three types of interaction. American Journal of Distance Education 3(2): 1-7.

Mott J (2010) Envisioning the post LMS Era: The open learning network. Educause Quarterly 33(1): 1-9.

Nickerson S and Sowder J (2002) What factors influence the formation of teachers' professional communities and why should we care? Paper presented at the $26^{\text {th }}$ annual meeting of the International Group for the Psychology of Mathematics Education, Norwich, England, July.

Oliver R (2001) Assuring the quality of online learning in Australian higher education. In: Proceedings of moving online II conference (ed M Wallace, A Ellis and D Newton), pp. 222-31. December 9-13, Southern Cross University: Lismore, NSW, Australia..

Parry B (2008) Twitter for academia. Available at: http://academhack.outsidethetext.com/home/ 2008/Twitter-for-academia/ (accessed 17 December 2012).

Prestridge S (2009) Teachers' talk in professional development activity that supports change in their ICT pedagogical beliefs and practices. Teacher Development 13(1): 43-55.

Prestridge S (2010) ICT professional development for teachers in online forums: Analysing the role of discussion. Teaching and Teacher Education 26(2): 252-8.

Reid J (2011) 'We don't Twitter, we facebook': An alternative pedagogical space that enables critical practices in relation to writing. English Teaching: Practice and Critique 10(1): 58-80. 
Reuben R (2008) The use of social media in higher education for marketing and communications: A guide for professionals in higher education. Available at: http://doteduguru.com/id423-social-media-useshigher-education-marketing-communication.html (accessed 17 December 2012).

Schwandt T (1994) Constructivist, interpretivist approaches to human inquiry. In: Denzin N and Lincoln Y (eds) Handbook of Qualitative Research. Thousand Oaks, CA: SAGE, pp. 118-37.

Sharpe B (2006) The ambient web. In: BETCA (ed.) Emerging Technologies for Learning. Coventry: British Educational Communications and Technology Agency, pp. 16-31.

Smith P and Ragan T (2005) Instructional Design. Hoboken, NJ: Wiley \& Sons.

Sweeney T (2012) The ACCE 2012 study tour: Reflections and reoccurring themes. Australian Educational Computing 7(1): 7-11.

Taylor P and Keeters S (2010) Students: A Portrait of a Generation. Washington, DC: Pew Research Centre.

Turcsányi-Szabo M (2012) Aiming at sustainable innovation in teacher education - from theory to practice. Informatics in Education 11(1): 115-30.

Veletsianos G and Kimmons R (2013) Scholars and faculty members lived experiences in online social networks. The Internet and Higher Education 16(1): 43-50.

Veletsianos G and Navarrete C (2012) Online social networks as formal learning environments: Learner experiences and activities. The International Review of Research in Open and Distance Learning 13(1): 144-66.

Veletsianos G, Kimmons R and French K (2013) Instructor experiences with a social networking site in a higher education setting: Expectations, frustrations, appropriations, and compartmentalization. Education Technology Research and Development 61(2): 255-78.

Wenger E (1998) Communities of Practice: Learning, Meaning and Identify. Cambridge, MA: Cambridge University Press.

\section{Author biography}

Sarah Prestridge's research broadly encompasses the use of technology in education, focusing on teacher beliefs and how they inform classroom practice, the use of information and communications technology (ICT) as a tool for learning and online professional development. She is currently a researcher on a National Grant to investigate the use of digital games in the curriculum. Address: Griffith University, Mt Gravatt Campus, Brisbane, QLD 4111, Australia. [email: s.prestridge@griffith.edu.au] 